Original Article

\title{
The effect of the correlation between the contraction of the pelvic floor muscles and diaphragmatic motion during breathing
}

\author{
Hankyu Park, MSc, $\mathrm{PT}^{1)}$, Dongwook Han, PhD, $\mathrm{PT}^{2)^{*}}$ \\ 1) Department of Physical Therapy, Graduate School of Rehabilitation Science, Daegu University, \\ Republic of Korea \\ 2) Department of Physical Therapy, College of Health and Welfare, Silla University: 700 beon-gil, 140 \\ Baegyang-daero, Sasang-gu, Busan 617-736, Republic of Korea
}

\begin{abstract}
Purpose] This study was conducted to investigate the effect of the correlation between the pelvic floor muscles (PFM) and diaphragmatic motion during breathing. [Subjects] The subjects of this study were 20 healthy female students who listened to an explanation of the study methods, purpose and agreed to participate in the experiment. [Methods] Radiograph equipment was used to examine diaphragmatic motion with contraction of the PFM during breathing, and a spirometer was used to examine lung vital capacity. [Results] The results revealed a significant change in the diaphragmatic motion and pulmonary function ( $\left.\mathrm{FEV}_{1}, \mathrm{MVV}\right) . \mathrm{FEV}_{1}$ and MVV showed significant differences when the PFM was contracted. Diaphragmatic motion showed a significant difference when the PFM was contracted. [Conclusion] Diaphragmatic motion and contraction of the PFM correlate with breathing. In addition, breathing is much more effective during contraction of the PFM. Therefore, PFM strengthening exercises should be included in respiratory rehabilitation programs.

Key words: Abdominal muscles, Diaphragm, Pelvic floor muscle
\end{abstract}

(This article was submitted Feb. 23, 2015, and was accepted Mar. 24, 2015)

\section{INTRODUCTION}

During a state of rest, inspiration is caused by a contraction of the inspiration muscles and expiration is caused by a relaxation of the inspiration muscles. In a situation that requires a lot of oxygen, such as during exercise, breathing is caused by the contraction of inspiration and expiration muscles ${ }^{1)}$. In breathing, the diaphragm, the principal muscle of respiration, plays a significant role in the maintenance of breathing ${ }^{2)}$. When the diaphragm is contracted, it causes inspiration, and when the diaphragm is relaxed, it causes expiration. At that moment, diaphragmatic motion is affected by the contraction of abdominal muscles. The downward movement of the diaphragm decreases even though the diaphragm is contracted because intra-abdominal pressure (IAP) increases when abdominal muscles are contracted during inspiration. In addition, expiratory flow can be increased because the IAP makes the diaphragm move upward when the abdominal muscles are contracted during the relaxation of the diaphragm during expiration. In contrast, when both the abdominal muscles and the diaphragm are contracted at

*Corresponding author. Dongwook Han (E-mail: dwhan@ silla.ac.kr)

(C2015 The Society of Physical Therapy Science. Published by IPEC Inc. This is an open-access article distributed under the terms of the Creative Commons Attribution Non-Commercial No Derivatives (by-ncnd) License $<$ http://creativecommons.org/licenses/by-nc-nd/3.0/> . the same time, IAP increases ${ }^{3)}$. Allison et al. ${ }^{2)}$ confirmed that the stability of a trunk can be enhanced if there is an IAP that is generated by the simultaneous contraction of both the diaphragm and abdominal muscles. Thus, the diaphragm is involved with breathing and providing trunk stability along with the abdominal muscles.

Among the muscles involved in IAP and breathing, the pelvic floor muscles (PFM) are often ignored. Bartelink ${ }^{4)}$ confirmed that the diaphragm moves upward and the PFM moves downward when abdominal muscles are contracted. Cresswell et al. ${ }^{3)}$ explained that the diaphragm moves upward and the increased IAP induces a contraction of the PFM when abdominal muscles are strongly contracted. Therefore, the PFM is relaxed during inspiration but is also contracted to protect internal organs when the IAP drastically increases. The PFM is contracted even during a strong expiration period and, at this time, the IAP increases leading to the upward movement of the diaphragm. Consequently, the PFM should be responsible for reacting to and controlling changes of IAP along with the abdominal muscles and diaphragm. Neumann and Gill ${ }^{5)}$ reported that contraction of the PFM generated activation of the transverse abdominis and internal oblique, and also raised the IAP by $6 \mathrm{mmHg}$. Additionally, Bø et al. ${ }^{6}$ and Sapsford ${ }^{7)}$ confirmed that the PFM are involved in changes of IAP and also trunk stability, which is required in breathing and coughing, contracting simultaneously when both the diaphragm and anterolateral abdominal muscles are contracted. Thus, the PFM does not independently contract itself but reacts and controls changes 
of IAP by systematically working together with the diaphragm and surrounding abdominal muscles, especially with the anterolateral abdominal muscles ${ }^{8)}$. Therefore, the PFM protect the internal organs in the pelvis and continuously works to control IAP when you talk, move, breathe, cough, or even move your limbs ${ }^{9,10)}$.

As mentioned, even though the PFM has breathingrelated functions, most studies of the PFM have investigated urological diseases ${ }^{11,12)}$. This study attempted to identify the effect of the contraction of the PFM and diaphragmatic motion during breathing.

\section{SUBJECTS AND METHODS}

The subjects of this study were 20 healthy female students of S university, Busan, Republic of Korea. They participated in the experiment after being informed of the procedures of the experiment. This study complied with the ethical standards of the Declaration of Helsinki, and written informed consent was received from each participant. The ethical committee of Silla University approved this study. None of the subjects had a history of musculoskeletal disorders, smoking, congenital deformity of the thoracic cavity, or rib fracture in the past 6 months. The characteristics of the subjects were as follows: age of 22.5 years, height of $160.6 \mathrm{~cm}$, weight of $53.0 \mathrm{~kg}$.

In this study, a radiograph (Digital Surgical C-Arm XRay System ZEN-2090, Philips, Netherlands) was used to examine diaphragmatic motion with contraction of the PFM during breathing. Diaphragmatic motion was measured before and during contraction of the PFM in a supine position. The measurements were conducted three times and the average value was adopted. A one-minute rest was given after every trial to prevent muscle fatigue. A spirometer (Pony FX, Cosmed, Italy) was used to examine lung vital capacity. Measurements were made of Forced Vital Capacity (FVC) and Maximum Voluntary Ventilation (MVV). The shoulders of the participants were restrained to reduce compensation by the trunk, and both nostrils were blocked during pulmonary function measurements. The measurements were performed before and during contraction of the PFM. They were repeated three times and the average value was adopted. A one-minute rest was given after every trial to prevent muscle fatigue, and sufficient rest was also given after every measurement.

Wilcoxon's Signed Rank test was used to examine the relationship of contraction of the PFM, diaphragmatic motion and changes in pulmonary function. Statistical analysis was conducted using SPSS 21.0 for Windows. Significance was accepted for values of $\mathrm{p}<0.05$.

\section{RESULTS}

FVC and peak expiratory flow (PEF) decreased during contraction of the PFM, but the differences were not significant. On the other hand, $\mathrm{FEV}_{1}$ significantly decreased $(p<0.05)$. MVV significantly increased during contraction of the PFM $(p<0.05)$, and diaphragmatic motion significantly decreased during contraction of the PFM $(\mathrm{p}<0.05)$ (Table 1).
Table 1. The changes in pulmonary function and diaphragmatic motion between before and during contraction of the pelvic floor muscles (Unit)

\begin{tabular}{|c|c|c|c|c|}
\hline Variables & $\begin{array}{c}\text { Before } \\
\text { contraction }\end{array}$ & $\begin{array}{c}\text { During } \\
\text { contraction }\end{array}$ & $\begin{array}{c}\text { Mean } \\
\text { rank }\end{array}$ & $\begin{array}{c}\text { Rank } \\
\text { sum }\end{array}$ \\
\hline FVC & $2.8 \pm 0.4^{\mathrm{a}}$ & $2.7 \pm 0.4$ & $\begin{array}{c}12.6 \\
8.0\end{array}$ & $\begin{array}{c}138.0 \\
72.0\end{array}$ \\
\hline $\begin{array}{l}\mathrm{FVC} \\
\text { (1) } \mathrm{FEV}_{1}{ }^{*}\end{array}$ & $2.3 \pm 0.4$ & $2.1 \pm 0.4$ & $\begin{array}{c}11.1 \\
8.8\end{array}$ & $\begin{array}{c}166.0 \\
44.0\end{array}$ \\
\hline PEF & $4.4 \pm 1.7$ & $4.1 \pm 1.7$ & $\begin{array}{c}9.4 \\
14.8\end{array}$ & $\begin{array}{c}151.0 \\
59.0\end{array}$ \\
\hline $\begin{array}{l}\text { MVV } \\
(1 / \mathrm{min})^{*}\end{array}$ & $87.5 \pm 18.0$ & $97.7 \pm 16.4$ & $\begin{array}{c}0.0 \\
10.5\end{array}$ & $\begin{array}{c}0.0 \\
210.0\end{array}$ \\
\hline $\begin{array}{l}\text { Diaphragm } \\
(\mathrm{cm})^{*}\end{array}$ & $6.0 \pm 0.7$ & $5.6 \pm 0.5$ & $\begin{array}{l}9.5 \\
0.0\end{array}$ & $\begin{array}{c}171.0 \\
0.0\end{array}$ \\
\hline
\end{tabular}

${ }^{a}$ Mean \pm SD, ${ }^{*} \mathrm{p}<0.05$ by Wilcoxon's Signed Rank Test

FVC: forced vital capacity, $\mathrm{FEV}_{1}$ : forced expiratory volume in one second, PEF: peak expiratory flow, MVV: maximum voluntary ventilation

\section{DISCUSSION}

The abdominal cavity, which is shaped like a balloon, is composed of abdominal muscles at the front and right side, para spinal muscles at the back, the diaphragm in the upper abdomen, and the PFM in the lower abdomen. Due to its structure, the PFM does not contract on its own but contracts in cooperation with muscles around the abdominal area ${ }^{13,14)}$. In general, when there is an IAP is generated by speaking, breathing, or coughing, the pressure is delivered in all directions in the abdominal cavity through the organs and ascites. Abdominal muscles like the PFM and diaphragm contract together to protect the organs against the pressure ${ }^{9}$. Through this procedure, the PFM are indirectly involved in breathing. It is well-known that the PFM relax during inspiration to help the diaphragm move downward, allowing inspiratory flow to increase. They also contract together with the abdominal muscles during exhalation or coughing to help the diaphragm move upward by increasing the IAP ${ }^{4}$. This study examined the effect of PFM' contraction on diaphragmatic motion and pulmonary function; this study was much needed, as few studies exist on this topic. This study confirmed that the contraction of the PFM is involved in diaphragmatic motion and affects pulmonary function.

The range of diaphragmatic motion is reported to be approximately $1.5 \mathrm{~cm}$ during quiet breathing and 6 to $10 \mathrm{~cm}$ during deep breathings such as in sports ${ }^{15)}$. Our results show a similar result, a $6.0 \mathrm{~cm}$ range of motion in the diaphragm before the PFM was contracted. There was a significant decrease of $5.6 \mathrm{~cm}$ during the contraction of the PFM. This result indicates that contraction of the PFM hinders the movement of the diaphragm. In conclusion, the results of this study indicate that IAP is increased because abdominal muscles also contract when the PFM are contracted. Additionally, an increase in IAP occurs hindering the downward movement of the diaphragm.

This limitation of the downward movement of the diaphragm may affect pulmonary function. Our results show 
there were changes in pulmonary function: FVC and PEF decreased, but their decreases were not statistically significant. Normally, FVC is affected by the movement of the thorax and by the strength of the diaphragm and respiratory muscles ${ }^{16)}$. It is known that FVC can decrease because the lung cannot fully expand due to lack of thorax movement in cases of chest wall diseases, such as kyphosis ${ }^{17)}$. Under these circumstances, FVC is decreased due to limitations in the range of thorax movement which hinder diaphragmatic motion, resulting in an increase in IAP, because the abdominal muscles contract while the PFM is contracting. Our study subjects did not exhibit statistically significant differences because they were all normally healthy females. Even when their PFM were contracted, downward movement was only partially inhibited because the subjects' diaphragms and muscle strength were normal. Conversely, FEV 1 significantly decrease during PFM contraction. Normally, decreases in $\mathrm{FEV}_{1}$ indicate a pathological abnormality in the airway since it is a variable that is highly correlated with airway resistance ${ }^{18)}$. In this study, because the subjects were normally healthy, airway resistance or airway obstruction cannot explain the significant decrease observed in $\mathrm{FEV}_{1}$. Generally speaking, the IAP increases during strong expiration, forcing the diaphragm into a parachute shape, expelling air from the thorax to the outside ${ }^{19}$ ). Therefore, in the case of a normal person, it can be predicted that higher IAP will result in a higher $\mathrm{FEV}_{1}$. However, in this study, abdominal muscles were contracted since the PFM was already contracted before the diaphragm began to contract. This is because increased IAP limited the downward movement of the diaphragm before the diaphragm began to contract. The limitation caused a decrease in $\mathrm{FEV}_{1}$ by hindering the maximum contraction, which is based on the Frank-Starling mechanism ${ }^{20)}$. This mechanism explains the maximum contraction that may be produced by relaxing both the PFM and abdominal muscles. In this study, MVV increased even more while the PFM were contracting. MVV is a measurement of the ability to continuously maintain a high level of air flow, and it is an important indicator in the evaluation of motor ability ${ }^{21)}$. In the results of this study, the increase in MVV due to PFM' contraction suggests that contraction is very important for the maintenance of breathing ability during exercise. MVV depends on the maximum respiratory volume of the lungs in one breath. It depends on the lung capacity and the speed by which the volume of air can move in and out. It also depends on the elasticity of the lungs and thorax, the muscle power of the respiratory muscles, and the resistance of the airways and thorax ${ }^{22)}$. The results of this study suggested that MVV increased due to an increase in the speed of inspiration and expiration and contraction and relaxation of the PFM and abdominal muscles is unnecessary because the PFM contracts in advance.

In conclusion, the results of this study suggest that PFM strengthening exercises should be included in respiratory rehabilitation programs because the PFM can affect diaphragmatic motion and pulmonary function. However, this study was not able to directly identify the correlation between the muscle power of the PFM, diaphragmatic motion, and pulmonary function. Therefore, further studies are needed to identify the effects of PFM strengthening on pulmonary function through PFM strengthening exercises.

\section{REFERENCES}

1) Ratnovsky A, Elad D, Halpern P: Mechanics of respiratory muscles. Respir Physiol Neurobiol, 2008, 163: 82-89. [Medline] [CrossRef]

2) Allison GT, Kendle K, Roll S, et al.: The role of the diaphragm during abdominal hollowing exercises. Aust J Physiother, 1998, 44: 95-102. [Medline] [CrossRef]

3) Cresswell AG, Grundström H, Thorstensson A: Observations on intraabdominal pressure and patterns of abdominal intra-muscular activity in man. Acta Physiol Scand, 1992, 144: 409-418. [Medline] [CrossRef]

4) Bartelink DL: The role of abdominal pressure in relieving the pressure on the lumbar intervertebral discs. J Bone Joint Surg Br, 1957, 39-B: 718-725. [Medline]

5) Neumann P, Gill V: Pelvic floor and abdominal muscle interaction: EMG activity and intra-abdominal pressure. Int Urogynecol J Pelvic Floor Dysfunct, 2002, 13: 125-132. [Medline] [CrossRef]

6) Bø K, Lilleås F, Talseth T, et al.: Dynamic MRI of the pelvic floor muscles in an upright sitting position. Neurourol Urodyn, 2001, 20: 167-174. [Medline] [CrossRef]

7) Sapsford R: Rehabilitation of pelvic floor muscles utilizing trunk stabilization. Man Ther, 2004, 9: 3-12. [Medline] [CrossRef]

8) Bø K: Pelvic floor muscle training is effective in treatment of female stress urinary incontinence, but how does it work? Int Urogynecol J Pelvic Floor Dysfunct, 2004, 15: 76-84. [Medline] [CrossRef]

9) Hodges PW, Sapsford R, Pengel LH: Postural and respiratory functions of the pelvic floor muscles. Neurourol Urodyn, 2007, 26: 362-371. [Medline] [CrossRef]

10) Talasz H, Kofler M, Kalchschmid E, et al.: Breathing with the pelvic floor? Correlation of pelvic floor muscle function and expiratory flows in healthy young nulliparous women. Int Urogynecol J Pelvic Floor Dysfunct, 2010, 21: 475-481. [Medline] [CrossRef]

11) Kasawara KT, Duarte CB, Ferreira NO, et al.: Behavioral therapy and pelvic floor muscle training in the treatment of infantile insensible urinary incontinence: a case report. J Phys Ther Sci, 2013, 25: 355-356. [CrossRef]

12) Tajiri K, Huo M, Maruyama H: Effects of co-contraction of both transverse abdominal muscle and pelvic floor muscle exercises for stress urinary incontinence: a randomized controlled trial. J Phys Ther Sci, 2014, 26: 1161-1163. [Medline] [CrossRef]

13) Sapsford RR, Hodges PW: Contraction of the pelvic floor muscles during abdominal maneuvers. Arch Phys Med Rehabil, 2001, 82: 1081-1088. [Medline] [CrossRef]

14) Sapsford RR, Hodges PW, Richardson CA, et al.: Co-activation of the abdominal and pelvic floor muscles during voluntary exercises. Neurourol Urodyn, 2001, 20: 31-42. [Medline] [CrossRef]

15) Gatzoulis MA: Anatomy of breathing. In: Standring Susan (ed) Gray's Anatomy, 40th ed. Churchill Livingstone, 2008, pp 1011-1012.

16) Um KM, Yang YK, Park SY: Effect of pulmonary function by winter intensive training (baseball player). J Korean Aca Phys Ther, 1999, 6: 9971005 .

17) Lee SY: Comprehension and Interpretation of Pulmonary Function Test. Medbook, 2003, pp 6-10.

18) Lee BK: The effect of the forced pulmonary function of young female, by changes in lung function related to postures and by transverse abdominis activation in standing position. J Korean Soc Phys Med, 7: 267-274. [CrossRef]

19) De Troyer A: Actions of the respiratory muscles or how the chest wall moves in upright man. Bull Eur Physiopathol Respir, 1984, 20: 409-413. [Medline]

20) Gosselink AT, Blanksma PK, Crijns HJ, et al.: Left ventricular beat-to-beat performance in atrial fibrillation: contribution of Frank-Starling mechanism after short rather than long RR intervals. J Am Coll Cardiol, 1995, 26: 1516-1521. [Medline] [CrossRef]

21) Ryu HM, Choi HJ, Jo YB, et al.: The role of MIRF in determining MVV in patients with chronic obstructive pulmonary disease. J Korean Med, 1996, 50: 537-543.

22) Fishman AP: Pulmonary disease and disorders, 2nd ed. New York: McGraw-Hill Book, 1988, pp 2469-2541. 